\title{
Levels of Professionalism among Physical Therapists in India- A National Cross-Sectional Survey
}

\section{Senthil P Kumar ${ }^{1 *}$, Vaishali Sisodia ${ }^{2}$ and Ernest Jacob ${ }^{3}$}

${ }^{1}$ Associate Professor in Musculoskeletal and Manual Therapy, Dept of Physiotherapy, Kasturba Medical College, Manipal University, Mangalore, India ${ }^{2}$ Department of Physiotherapy, Career Institute of Medical Sciences, Bhopal, India

${ }^{3}$ Assistant Professor, Dr. M.V.Shetty College of Physiotherapy, Mangalore, India

\begin{abstract}
Background and purpose: The American Physical Therapy Association (APTA) developed the core values of leadership, administration, management and professionalism for physical therapists. The aim of this study was to assess the levels of professionalism among physical therapists in India.
\end{abstract}

Materials and methods: This cross-sectional study was done using a survey questionnaire- Professionalism In Physical Therapy- Core Values (PPTCV) instrument that consisted of sample indicators for each of the seven core values- accountability (10 indicators), altruism (5 indicators), compassion/caring (11 indicators), excellence (11 indicators), integrity (12 indicators), professional duty (7 indicators), and social responsibility (12 indicators). Each sample indicator was to be rated using a 5-point Likert scale from 'never, rarely, occasionally, frequently and rarely.' 771 eligible questionnaires out of 889 participants with a response rate of $91.33 \%$ were analyzed and computed based upon individual- and profession-related variables. Descriptive analysis was done using SPSS version 11.5 (SPSS Inc, IL) at $95 \%$ confidence interval.

Results: Overall, high levels of professionalism was reported by post-graduate students, followed by researchers and teaching faculty. Younger male physical therapy students were more likely to report high levels of professionalism. Individually, accountability was high among teaching faculty, altruism, compassion/caring and social responsibility among clinician-therapists, and integrity and professional duty was high among researchers. No single professional category showed high levels of professionalism in all seven core values.

Conclusion: Overall levels of professionalism among Indian physical therapists were moderate, and altruism and compassion levels were also low. Other indicators of professionalism were fairly evenly distributed among the students and therapists, and between genders. The study findings are of importance to develop curricular and educational modifications to improve levels of professionalism among physical therapists in India and future studies are warranted around the world.

Keywords: Professionalism; Leadership; Administration; Management; Professional development

\section{Introduction}

Professionalism may be defined as; "the qualities or typical features of a profession or of professionals, especially competence, skills and code of behavior that maintains the ethics and dignity of the profession [1]. Professionalism in physical therapy includes those aspects of the occupational control of work which are in the best interests of customers, clients and patients, as well as in the advice-giving, lobbying and sometimes oppositional aspects of professions' relations with states, legislative bodies, and regional and local administrative agencies [2]. The other related term is professionalization that is often appropriately understood as development of profession while professionalism is development of professionals per se. Professionalization is a series of diverse and variable, social and historical processes of development, of how work sometimes becomes an occupation, and how occupations achieve various forms of occupational control of work sometimes called professional [3].

The earliest mentioning of professionalism in medicine was in the Hippocratic oath and ever since then, had been evolving through a series of milestones from 1847 when American Medical Association (AMA) code of medical ethics was established until 2002 when the physician's charter was formed [4]. The profession of physical therapy evolved from a medically directed clinical decision-making in treating patients to an autonomous direct-access service [5]. With growth in practice autonomy, there is an increased need for professional accountability which improves quality of provided care [6,7].

In 2003, the American physical therapy association developed the core values definition and included it as part of credentials and requirements for entry-level PT programmes [8]. In 2004, the eleven ethical principles were established by American Physical Therapy Association (APTA) as the Guide for professional conduct that involved the core values necessary for professional autonomy and interprofessional care [9]. Understanding the current levels of professionalism not only provides a baseline information upon which to further develop using educational and professional development strategies, but also to facilitate enhanced professionalization by addressing individual- and professional-related factors. The objective of the present study was to assess the levels of professionalism and core values among physical therapists in India.

\section{Materials and Methods}

The study design was an assessor-blinded cross-sectional study The study was conducted at Dept of Physiotherapy; Kasturba Medical College (Manipal University), Mangalore and data was collected from

*Corresponding author: Senthil $P$ Kumar, Associate Professor in Musculoskeletal and Manual Therapy, PhD Candidate, Department of Physiotherapy, Kasturba Medical College (Manipal University), Mangalore, India, E-mail: senthil.kumar@manipal.edu

Received June 29, 2013; Accepted August 21, 2013; Published August 28, 2013

Citation: Kumar SP, Sisodia V, Jacob E (2013) Levels of Professionalism among Physical Therapists in India- A National Cross-Sectional Survey. J Sports Med Doping Stud 3: 123. doi:10.4172/2161-0673.1000123

Copyright: ( 2013 Kumar SP, et al. This is an open-access article distributed under the terms of the Creative Commons Attribution License, which permits unrestricted use, distribution, and reproduction in any medium, provided the original author and source are credited. 
the conference participants at the $48^{\text {th }}$ annual conference of Indian Association Of Physiotherapists (IAP), a national physiotherapy conference organized by Mangalore branch of IAP, from 21-23 January 2010. The APTA core values of professionalism self-evaluation form which were named as professionalism in Physical Therapy- Core Values (PPTCV) instrument was used for the data collection [10]. The survey questionnaire consisted of sample indicators for each of the seven core values- 1 ) accountability (10 indicators), 2) altruism (5 indicators), 3) compassion/caring (11 indicators), 4) excellence (11 indicators), 5) integrity (12 indicators), 6) professional duty (7 indicators), and 7) social responsibility (12 indicators). Each sample indicator was to be rated using a 5-point Likert scale from 'never, rarely, occasionally, frequently and rarely. The questionnaire was designed for self-assessment and was validated and used previously.

All participants signed a written informed consent prior to answering the survey. The questionnaires were coded to ensure participant anonymity and privacy and confidentiality of obtained data. The data was collected by physiotherapy students and/or interns who were volunteers in the conference and were blinded from the purpose of the study.

\section{Data synthesis}

We considered seven professional categories (profession-related variables): under-graduate or entry-level student $\left(2^{\text {nd }}\right.$ year, $3^{\text {rd }}$ year, final year), intern, post-graduate student, practising therapist (private practitioner, hospital-based), educator/ teacher-faculty (freelancer, institution-based), researcher and administrator. Age and gender were considered as person-related variables. The overall scores and score of each of the seven core values were thus compared across the categories.

\section{Data analysis}

The questionnaire involved five-point Likert scaling and we converted the categorical variables into continuous by coding them according to their ascending order of emphasis eg, score-1 for 'never' and score- 5 for 'always' as recommended by APTA scoring instructions. Thus we could compute means and standard deviations for the obtained scores for each core value, and total scores. We arbitrarily assigned the total scores and sub-scores categorized into six: $<15 \%$ very low; $16-30 \%$ - low; $31-45 \%$ - moderate; $46-60 \%$ - fair; $61-75 \%$ - high; and, $>75 \%$ - very high. The percentiles were obtained from calculating proportion of obtained scores with respect to total achievable scores. One-way analysis of variance (ANOVA) was used for between-group comparisons (professional and personal-related groups) and betweencore value comparisons. Friedman's test was used for all comparisons of categorical variables. All analysis was done using SPSS version 16.0 (SPSS Inc, IL) at 95\% confidence interval.

\section{Results}

\section{Sample size estimation}

There are a total 50,000 physiotherapists and 20,000 physiotherapy students in the country. Annually, the attendance of this conference ranges around 3,000 in which 500 may be students making it $85 \%$ physical therapists and $15 \%$ students. We arbitrarily anticipated moderate levels of professionalism among the participants at 50\%$60 \%$ range scores in the questionnaire. Since the total score for the questionnaire is 345 , the required score range was from 173-207. Hence using the sample size estimation formula we needed to recruit a minimum of 750 participants at $90 \%$ power and 5\% type-1 error (alpha) [11]. To get a final number of 750, we needed to consider 1250 participants at a response rate of $60 \%$ (Table 1 ).

$\mathrm{N}=\mathrm{Z}^{2}(1-\infty / 2) \mathrm{P}(1-\mathrm{P}) / \mathrm{e}^{2}$

$\mathrm{N}$ - Number of sample

$Z^{2}-(1.96)^{2}$ for $95 \%$ confidence interval (i.e., $a=0.05$ or $5 \%$ )

P- Best guess for prevalence (eg, \pm 0.50$)$

e- Maximum tolerable/ acceptable error for the prevalence estimate (eg, \pm .05 or $5 \%)$

The survey was administered to 889 physical therapists and students, and 812 completed questionnaires were received with a response rate of $91.33 \%$. The participants were selected by convenient sampling. After scrutiny, 771 eligible questionnaires were then analyzed and computed based upon individual- and profession-related variables.

\section{Primary outcomes}

The overall scores of PPT-CV for each of its core values are provided in table 2 and comparison between professional categories is given in table 3 and figure 1 .

Though the female $(145.24 \pm 40.94)$ physical therapists had a higher overall score in PPT-CV than their male counterparts (140.02 \pm 39.78$)$, the difference was not statistically significant $(\mathrm{p}=0.088)$. Age had a strong positive correlation $(\mathrm{r}=0.809)$ with total scores of $\mathrm{PPT}-\mathrm{CV}$ which was statistically significant $(\mathrm{p}=0.000)$.

\begin{tabular}{|c|c|c|c|c|}
\hline Variables & \multicolumn{2}{|l|}{ Sub-categories } & Values- individual & $\begin{array}{c}\text { Values- total } \\
N(\%)\end{array}$ \\
\hline Sample size, $N$ & & & & 771 \\
\hline \multirow{2}{*}{$\begin{array}{l}\text { Gender } \\
N(\%)\end{array}$} & Male & & & $319(41.37 \%)$ \\
\hline & Female & & & $452(58.63 \%)$ \\
\hline Age (years) Mean \pm SD & & & & $26.54 \pm 4.87$ \\
\hline \multirow{9}{*}{ Professional categories } & \multirow{4}{*}{$\begin{array}{l}\text { Student/ } \\
\text { intern }\end{array}$} & $2^{\text {nd }}$ year & 13 & \multirow{4}{*}{$376(48.76 \%)$} \\
\hline & & $3^{\text {rd }}$ year & 78 & \\
\hline & & Final year & 157 & \\
\hline & & Intern & 128 & \\
\hline & \multirow{5}{*}{ Professional } & PG student & 88 & \multirow{5}{*}{$395(51.24 \%)$} \\
\hline & & $\begin{array}{l}\text { Practising } \\
\text { therapist }\end{array}$ & 114 & \\
\hline & & Educator & 185 & \\
\hline & & Researcher & 6 & \\
\hline & & Administrator & 2 & \\
\hline
\end{tabular}

Table 1: Overall demographic characteristic of participants. 
Citation: Kumar SP, Sisodia V, Jacob E (2013) Levels of Professionalism among Physical Therapists in India- A National Cross-Sectional Survey. J Sports Med Doping Stud 3: 123. doi:10.4172/2161-0673.1000123

Page 3 of 2

\begin{tabular}{|c|c|c|c|c|}
\hline Core values & Number of indicators & Total score & Obtained score (overall) & Obtained $(\%)$ overall \\
\hline Accountability & 10 & 50 & $22.37 \pm 9.76$ & $44.74 \%^{a}$ \\
\hline Altruism & 5 & 25 & $12.11 \pm 4.16$ & $48.44 \%^{\mathrm{b}}$ \\
\hline Compassion/ caring & 11 & 55 & $25.39 \pm 8.42$ & $46.16 \%^{b}$ \\
\hline Excellence & 11 & 55 & $23.35 \pm 7.68$ & $42.45 \%^{a}$ \\
\hline Integrity & 12 & 60 & $23.31 \pm 7.72$ & $38.85 \%^{a}$ \\
\hline Professional duty & 7 & 35 & $14.01 \pm 3.10$ & $40.02 \%^{a}$ \\
\hline Social responsibility & 12 & 60 & $22.51 \pm 7.22$ & $37.51 \%^{a}$ \\
\hline Total score & 69 & 345 & $143.08 \pm 40.52$ & $41.47 \%^{a}$ \\
\hline
\end{tabular}

aModerate level of professionalism

${ }^{\mathrm{b}}$ Fair level of professionalism

Table 2: Overall scores of PPT-CV for each of its seven subscales.

\begin{tabular}{|c|c|c|c|c|c|c|c|c|}
\hline \multirow{2}{*}{$\begin{array}{l}\text { Professional } \\
\text { category }\end{array}$} & \multicolumn{7}{|c|}{$\begin{array}{l}\text { Professionalism in physical therapy- core values } \\
\text { (PPT-CV) Sub scores }\end{array}$} & \multirow{2}{*}{$\begin{array}{c}\text { Total score (PPT- } \\
\text { CV) }\end{array}$} \\
\hline & Accountability & Altruism & Compassion & Excellence & Integrity & Professional duty & Social responsibility & \\
\hline $2^{\text {nd }}$ year & $7.33 \pm 1.18$ & $6.07 \pm 0.95$ & $13.84 \pm 2.11$ & $14.07 \pm 1.89$ & $14 \pm 2.19$ & $8.15 \pm 1.72$ & $13.84 \pm 2.11$ & $77.30 \pm 6.31$ \\
\hline $3^{\text {rd }}$ year & $10.92 \pm 2.30$ & $8.03 \pm 0.95$ & $16.87 \pm 1.65$ & $16.85 \pm 1.57$ & $16.74 \pm 1.7$ & $11.46 \pm 1.82$ & $16.21 \pm 2.38$ & $97.11 \pm 5.85$ \\
\hline Final year & $13.87 \pm 1.68$ & $8.56 \pm 0.94$ & $17.92 \pm 1.47$ & $17.94 \pm 1.47$ & $17.89 \pm 1.47$ & $12.47 \pm 2.05$ & $17.46 \pm 1.21$ & $106.13 \pm 3.95$ \\
\hline Intern & $17 \pm 1.70$ & $8.46 \pm 1.78$ & $16.96 \pm 2.13$ & $16.96 \pm 2.13$ & $16.9 \pm 2.05$ & $11.86 \pm 2.05$ & $17.65 \pm 2.37$ & $105.82 \pm 6.86$ \\
\hline PG student & $18.06 \pm 1.49$ & $12.54 \pm 1.12$ & $32.48 \pm 1.88$ & $32.23 \pm 1.94$ & $31.86 \pm 2.77$ & $13.01 \pm 1.8$ & $23.09 \pm 1.74$ & $163.30 \pm 5.40$ \\
\hline Practising the rapist & $32.09 \pm 2.04$ & $16.29 \pm 1.89$ & $36.5 \pm 2.86$ & $20.85 \pm 6.27$ & $21.14 \pm 6.54$ & $16.3 \pm 1.85$ & $37.25 \pm 2.72$ & $180.45 \pm 12.44$ \\
\hline Educator & $35.12 \pm 1.96$ & $16.96 \pm 1.26$ & $31.72 \pm 2.24$ & $39.16 \pm 0.75$ & $32.5 \pm 1.97$ & $17.02 \pm 1.23$ & $23.75 \pm 2.38$ & $189.69 \pm 4.74$ \\
\hline Researcher & $24 \pm 2.82$ & $14.5 \pm 1.87$ & $26.83 \pm 2.92$ & $32.6 \pm 1.26$ & $39.66 \pm 1.36$ & $24.5 \pm 1.04$ & $29 \pm 1.41$ & $197.66 \pm 2.16$ \\
\hline Administrator & $28 \pm 1.41$ & $8.5 \pm 0.70$ & $24 \pm 5.65$ & $21.5 \pm 3.53$ & $24.5 \pm 3.53$ & $14.5 \pm 3.53$ & $32.5 \pm 3.53$ & $153.50 \pm 19.09$ \\
\hline
\end{tabular}

Table 3: Scores of sub-scales (core values) compared between nine professional categories.

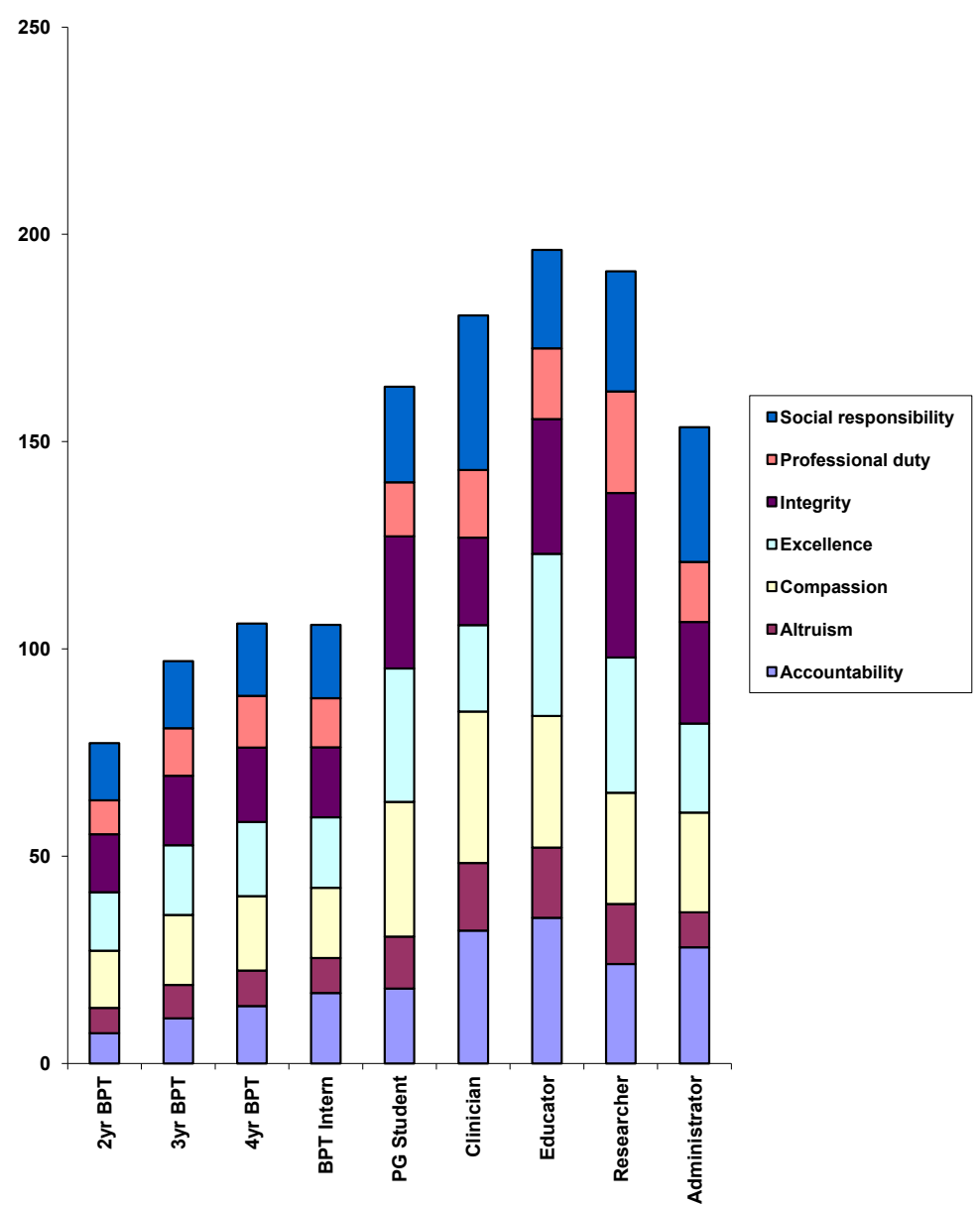

Figure 1: Comparison of scores of seven core values between the nine professional categories 
a $<15 \%$ - very low; b 16-30\%- low; c 31-45\%- moderate; d 46-60\%fair; e $61-75 \%$ - high; and, $\mathrm{f}>75 \%$ - very high

\section{Main findings- summary:}

Accountability=teaching faculty $>$ clinician-therapists $>$ administrat ors $>$ researchers $>$ post-graduate students $>$ interns $>4 \mathrm{BPT}>3 \mathrm{BPT}>2 \mathrm{BPT}$.

A l t r u is m $=\mathrm{clinician-therapist} s>t e a c h i n g$ faculty $>$ researchers $>$ interns $>$ post-graduate students $>$ administrators $>i$ nterns $>4 \mathrm{BPT}>3 \mathrm{BPT}>2 \mathrm{BPT}$

Compassion/caring $=$ clinician-therapists $>$ teaching faculty $>$ post graduate students $>$ interns $>$ researchers $>$ administrators $>$ interns $>4 \mathrm{BPT}$ $>3 \mathrm{BPT}>2 \mathrm{BPT}$

Excellence $=$ researchers $>$ post-graduate students $>$ teaching faculty $>$ clinician-therapists $>$ interns $>$ administrators $>4 \mathrm{BPT}>3 \mathrm{BPT}>2 \mathrm{~B}$ PT

Integrity $=$ researchers $>$ teaching faculty $>$ clinician-therapists $>$ postgraduate students $>$ administrators $>$ interns $>4 \mathrm{BPT}>3 \mathrm{BPT}>2 \mathrm{BPT}$

Professional duty $=$ researchers $>$ clinician-therapists $>$ post-graduate students $>$ teaching faculty $>$ administrators $>$ interns $>4 \mathrm{BPT}>3 \mathrm{BPT}>2 \mathrm{~B}$ PT

Social responsibility $=$ clinician-therapists $>$ administrators $>$ researc hers $>$ teaching faculty $>$ post-graduate students $>$ interns $>4 \mathrm{BPT}>3 \mathrm{BPT}>$ 2BPT

\section{Discussion}

\section{Factors influencing our findings}

Internal and external factors influence the actual or reported levels of professionalism [12]. The internal factors (clinician-related) are knowledge, attitudes, beliefs and behaviors, and external factors (organization-related, public opinion-related, and professional leadership- local and national) inevitably exert a huge influence on the assessed levels of professionalism, and this may hold good among the PTs. Knowledge, not only about theoretical construct related to education, practice and research, but also related to profession and professionalism per se, would exert a huge impact on the reported levels of professionalism [13]. Assessing and facilitating positive attitudes towards professionalism and empathy was often less emphasized/ reported in earlier studies. However, the actual behaviors might be different from attributions by individuals [14-16].

\section{Comparison of findings with similar studies}

We found higher scores of accountability, altruism, integrity, professional duty and social responsibility for PT interns compared to final/fourth year students, and such findings were reported earlier by Poirier and Gupchup who found increase in scores of accountability, altruism and integrity amongst pharmacy students from their first year to fourth year that the authors attributed to curricular and co-curricular activities in the institution $[17,18]$.

Teachers: have the responsibility to be as role models for students both in classroom and clinical environment. The counter-argument favors professionalism being absorbed and learnt so that it is integrated into one's behavior, and not taught per se $[19,20]$. Beauchamp opined that teachers have the obligation to educate their residents not only for healing and caring of patients but also for active participation in managing the healthcare system [21]. Saultz suggested four steps to overcome the challenges to improve teaching professionalism that can be taken in the medical education community [22]. First, medical schools should address cost and access to care as first-order intellectual problems and should encourage research programs in these areas. Second, schools should develop programs to humanize science and restore scientific integrity beyond the requirements of compliance programs. Next, medical school leaders should celebrate those who best embody moral leadership in the profession. Finally, the medical education community should acknowledge that the availability of affordable health care to the public depends on the practice choices of medical school graduates and should accept greater responsibility for this outcome. The above suggestions are applicable to PT as well.

List of recommendations put forth by Wear and Kuczewski [23]:

- Each medical school and residency program should be evaluated in terms of efforts to empower residents and medical students to address problems and deficits in the learning environment.

- Educators should enlist medical students and residents in developing a theory of professionalism through reflection on the activities these groups see as important to fostering their professionalism.

- The professionalism of students should be fostered by encouraging positive behaviors in each of the relationships that contribute to patient care and rewarding such behaviors. In other words, we must encourage residents and medical students when they exhibit leadership in professionalism and try to correct problems they see in the patient-care relationships around them.

- Teaching about professionalism must include education relating to social justice. Such justice education must include a macrocosmic picture of the economics of healthcare and a microcosmic picture of how injustice is reflected in the social and cultural barriers encountered daily within the clinic.

Clinical practitioners: Plochg et al. suggested seven strategies to transform professionalism to fit changing health needs: defining professionalism; creating supportive professional bodies; targeting research funding; targeting technology development; modernizing curricula; managing performance; and, developing supportive payment models. The core role of the practitioner was identified as having three components: dynamic practice, professional efficacy and clinical leadership [24,25]. In an era of consumerism in health care, professionalism equally should be emphasized and made to grow through two special initiatives: accountability and efficiency [26].

The moral obligations of a medical practitioner include "professional ethics" that regulate a wide range of professional conduct of which three types are of exceptional importance: preserving the focal values of the medical profession, protecting the Patient-Physician Relationship (PPR), and promoting the patient's best interest [27]. Robert Veatch, an American pioneer bioethicist, proposed four models of the PatientPhysician Relationship (PPR) in 1972: "engineering", "priestly", "collegial", and "contractual" [28]. Emanuel and Emanuel proposed another four PPR models: "paternalistic", "deliberative", "interpretive", and "informative". The roles of physician extend far from being mentors, to being technicians or contractors, or as friends or counselors [28,29].

Professionalism operates on a system of relationships: physicianpatient, physician-society, physician-health care system, physicianphysician, and physician-to-self [30]. The more recently evolved 'contractual model' and commercialization has lead to demise of medical professionalism by two ways- physician-owned clinical services and managed care payment policies [31]. Clinicians who had 
undergone continuing professional development programmes had improved levels of professionalism and they chose supervision as a method for self-directed professional development [32].

Suggestions for future studies: Studies' following up the students across a curriculum was done earlier amongst pharmacy students and such studies may be warranted to attribute factors responsible for changes in levels of professionalism [17]. Evaluation methodology for assessment of professionalism should be more quantitative such as Objective Structured Clinical Examination (OSCE) to evaluate separate elements and value conflicts and thereby to resolve them and recognize the contextual nature of professional behaviors and their environmental influences [33]. Professionalism can also be assessed using a combination of observed clinical encounters, multisource feedback, patients' opinions, paper-based tests or simulations, measures of research and/or teaching activities, and scrutiny of self-assessments compared with assessments by others [34].

Future studies are also indicated on assessment centers reported by Deusinger et al. which were implemented by Missouri Physical Therapy Association [35]. Such assessment centers enabled individuals to assess voluntarily their own practice competence and to use the results of the assessment to plan educational pursuits that might enhance professional growth. Bruhn advised three levels of aggressive intervention for improving professionalism among health care professionals- the professional organization, the organization one works for, and the individual- to revitalize good citizenship and professionalism [36].

Hayward and Blackmer found significant changes in PPTCV scores following doctor of physical therapy program in their institute [37]. The authors also found that those with high levels of professionalism had higher work-related self-efficacy and confidence. There is a scope for such interventional studies to be done among Indian PTs. With the ever-continuing growth in research in terms of randomized clinical trials and systematic reviews, and realization to 'think out of the box' into a rehabilitation framework in clinical practice necessitates.

\section{Conclusions}

Overall levels of professionalism among Indian physical therapists were moderate, and altruism and compassion levels were also low. Other indicators of professionalism were fairly evenly distributed among the students and therapists, and between genders. A relatively higher level of professionalism was observed with increase in age of the individual.

\section{Implications}

Professionalism is central to the survival of our profession. First, professionalism is the therapist's attitude and behavior in the practice of physical therapy. Second, it is a promise to serve not only the patient but also the society in which we practice. Third, it is accepting an unambiguous accountability to the healthcare system. It is a moral obligation. In a society overwhelmed by the spiraling cost of healthcare, we must be responsive to the state and the public which demands for accountability. There is a question of justice. Our own professional autonomy is related to our compliance with the values and needs of our community. On the other hand, it is our duty to resist any action that does not conform to the technical and moral ideal of the profession. There is no reason why anyone should become slaves to the healthcare system, consumers or the healthcare industry. Keeping a balance is not easy and requires courage. Finally, the teaching of professionalism and transmitting the soul of the profession is part of the profession's very long tradition and we have the responsibility to carry on this tradition [21]. The study findings thus are of importance to develop curricular and educational modifications to improve levels of professionalism among physical therapists in India and future studies are warranted around the world.

Future efforts at understanding professionalism, and future methods of evaluating professionalism, must focus on behaviors rather than personality traits or vague concepts of character. Our understanding and evaluation must include context and conflict in order to be relevant and valid. Ideally, methods of evaluation should include elements of peer assessment and self-assessment, which are becoming required elements in the continuing professional development of all practicing physicians. Finally, we should attempt to understand what drives students to demonstrate occasional lapses in professional behavior, in order to develop effective teaching and remediation in this domain [16].

\section{Acknowledgements}

The American Physical Therapy Association (APTA) for developing the survey instrument and granting permission for reprint and use in this study and the study participants for taking their valuable time to respond to the survey questionnaire. Prof Ifthikar Ali, organizing secretary of $48^{\text {th }}$ annual conference of Indian Association of Physiotherapists (IAP) and convener- IAP Mangalore branch for granting permission to collect the data.

\section{Related information}

The study was presented as a platform presentation in Chartered Society of Physiotherapy (CSP) 2011 Congress conducted on 7-8 ${ }^{\text {th }}$ October 2011 at BT convention center, Liverpool, UK. The presentation was done by SPK and was funded by Faculty Research Incentives Grant of Manipal University, India.

\section{References}

1. Swick HM (2000) Toward a normative definition of medical professionalism Acad Med 75: 612-616

2. Kumar SP (2011) Physical therapy- a review of realization of the need versus need for realization. Physiotimes 2: 12-15.

3. Marcus ER (1999) Empathy, humanism, and the professionalization process of medical education. Acad Med 74: 1211-1215.

4. Stevens RA (2002) Themes in the history of medical professionalism. Mt Sina J Med 69: 357-362.

5. Kumar SP (2010) Evolution of professional autonomy in physical therapy practice- a century-long walk through PubMed from 1910-2010. J Phys Ther 2: 1-10.

6. Schneller ES, Wilson NA (2009) Professionalism in $21^{\text {st }}$ century professional practice- autonomy and accountability in orthopaedic surgery. Clin Orthop Relat Res 467: 2561-2569.

7. Pawlson LG, O'Kane ME (2002) Professionalism, regulation and the market: impact on accountability for quality of care- physicians and accreditors need to respond to the market's emerging dominant influence on accountability. Health Aff 21: 200-207.

8. Davis DS (2009) Teaching professionalism: a survey of physical therapy educators. J Allied Health 38: 74-80.

9. Lopopolo RB, Schafer DS, Nosse LJ (2004) Leadership, administration, management, and professionalism (LAMP) in physical therapy: a Delphi study. Phys Ther 84: 137-150.

10. 10. American Physical Therapy Association (2003) Professionalism in physical therapy: core values- self-assessment. Alexandria, Virginia.

11. Sample size calculator (2012). National Statistical Service, Australian Bureau of Statistics, Locked Bag 10, Belconnen ACT 2616, Australia.

12. Ratanawongsa N, Bolen S, Howell EE, Kern DE, Sisson SD (2006) Residents' perceptions of professionalism in training and practice: barriers, promoters, and duty hour requirements. J Gen Intern Med 21: 758-763.

13. Kraemer WJ (2005) The body of knowledge: use and professionalism. Strength Cond Res 27: 33-35.

14. Jha V, Bekker HL, Duffy SRG, Roberts TE (2007) A systematic review of studies assessing and facilitating attitudes towards professionalism in medicine. Med Educ 41: 822-829. 
Citation: Kumar SP, Sisodia V, Jacob E (2013) Levels of Professionalism among Physical Therapists in India- A National Cross-Sectional Survey. J Sports Med Doping Stud 3: 123. doi:10.4172/2161-0673.1000123

15. Crandall SJ, Marion GS (2009) Identifying attitudes towards empathy: an essential feature of professionalism. Acad Med 84: 1174-1176.

16. Hickson GB, Pichert JW, Webb LE, Gabbe SG (2007) A complementary approach to promoting professionalism: identifying, measuring, and addressing unprofessional behaviors. Acad Med 82: 1040-1048.

17. Poirier TI, Gupchup GV (2010)Assessment of pharmacy student professionalism across a curriculum. Am J Pharm Educ 74: 62

18. Bennett AJ, Roman B, Arnold LM, Kay J, Goldenhar LM (2005) Professionalism deficits among medical students: models of identification and intervention. Acad Psychiatry 29: 426-432.

19. Harris GD (2004) Professionalism: part I- introduction and being a role model. Family Med 36: 314-315.

20. Hochberg MS, Kalet A, Zabar S, Kachur E, Gillespie C, et al. (2010) Can professionalism be taught? Encouraging evidence. Am J Surg 199: 86-93.

21. Beauchamp G (2004) The challenge of teaching professionalism. Ann Acad Med Singapore 33: 697-705.

22. Saultz JW (2007) Are we serious about teaching professionalism in medicine? Acad Med 82: 574-577.

23. Wear D, Kuczewski MG (2004) The professionalism movement: can we pause? Am J Bioeth 4:1-10.

24. Plochg T, Klazinga NS, Starfield B (2009) Transforming medical professionalism to fit changing health needs. BMC Med 7: 64 .

25. Carryer J, Gardner G, Dunn S, Gardner A (2007) The core role of the nurse practitioner: practice, professionalism and clinical leadership. J Clin Nurs 16: 1818-1825.

26. Imanaka Y (1999) Professionalism and consumerism: can they grow together? Int J Qual Health Care 9: 395-397.
27. Hui EC (2005) The physician as a professional and the moral implications of medical professionalism. Hong Kong Med J 11: 67-69.

28. Hui EC (2005) The centrality of patient-physician relationship to medica professionalism: an ethical evaluation of some contemporary models. Hong Kong Med J 11: 222-223.

29. Emanuel EJ, Emanuel LL (1992) Four models of the physician-patient relationship. JAMA 267: 2221-2226.

30. Walker KL, Arnold CL, Miller-Day M, Webb LM (2002) Investigating the physician-patient relationship: examining emerging themes. Health Commun 14: $45-68$.

31. Hui EC (2005) The contractual model of the patient-physician relationship and the demise of medical professionalism. Hong Kong Med J 11: 420-422.

32. Tulinius C, Holge-Hazelton B (2010) Continuing professional development for general practitioners: supporting the development of professionalism. Med Educ 44: 412-420.

33. Arnold L (2002) Assessing professional behavior: yesterday, today and tomorrow. Acad Med 77: 502-515.

34. Wilkinson TJ, Wade WB, Knock LD (2009)A blueprint to assess professionalism: results of a systematic review. Academic Medicine 84: 551-558.

35. Deusinger SS, Sindelar B, Stritter FT (1986) Assessment center- a model for professional development and evaluation. Phys Ther 66: 1119-1123.

36. Bruhn JG (2001) Being Good and Doing Good: The Culture of Professionalism in the Health Professions. Health Care Manag 19: 47-58.

37. Hayward LM, Blackmer B (2010) A model for teaching and assessing core values development in doctor of physical therapy students. J Phys Ther Educ 24: $16-26$. 